\title{
Social Network Analysis and Social Work Inquiry
}

Sue Gillieatt*, Christina Fernandes, Angela Fielding, Antonia Hendrick, Robyn Martin, \& Susi Matthews

School of Occupational Therapy \& Social Work, Faculty of Health Sciences, Curtin University

*Correspondence to: Sue Gillieatt, School of Occupational Therapy and Social Work, Faculty of Health Sciences, Curtin University, GPO Box U1987, Perth, Western Australia 6845. Email: s.gillieatt@curtin.edu.au

\begin{abstract}
Understanding and positively impacting social networks is core to social work practice and research. As a research method, social network analysis provides an important mechanism for mapping various types of networks as well as the relationships and exchanges between network actors. This has relevance to Australian human and health services given the social policy context that currently emphasises and requires improvements in the integration of services. This paper describes the application of social network analysis to a consortium of mental health and related services to examine indicators of service integration such as the frequency, type, and direction of information exchanges including referral pathways. When combined with other research methods and information, social network analysis is shown to be a useful tool providing both visual and sociometric evidence of relational activities, thus creating a strong basis for advocacy and social change.
\end{abstract}

Keywords: Social Network Analysis; Service Integration; Research

This research reviews how the methods and techniques of social network analysis (SNA) have been applied to social work inquiry, and describes how SNA was employed together with qualitative methods to explore the complexity of service integration. Service integration is examined in the environment of an Australian federally-funded program in which a 
consortium of 11 government and non-government organisations were tasked with overseeing the facilitation and delivery of coordinated mental health, primary health, employment, and alcohol and other drug services to a cohort of underserviced consumers and their families. Central to the consortium's brief is a commitment to strengthening network partnerships by developing linkages between services and improving referral pathways. The lead agency is responsible for the governance of the program and a team of clinicians from organisations in the consortium meet regularly to share information, conduct intake and review processes, raise community awareness, and strengthen integrated local responses to meet consumer needs. In order to enact confidentiality in this paper, general labels have been applied to the organisations and individuals involved. Hereafter, the host agency is referred to as the MHS and the program itself as the MHS program.

Our interest in utilising SNA to examine service integration was piqued by Australian social workers Gretchen Ennis and Deborah West, who used SNA techniques to portray the strengthening of organisational affiliations in a Northern Territory community (Ennis, 2011; Ennis \& West, 2010; Ennis \& West, 2012; Ennis \& West, 2013). For our project, we used SNA to obtain a baseline snapshot of the relationships between services in the MHS consortium and, in particular, the nature of information exchange and referral pathways. This was to give program staff access to key indicators about the relative health of the consortium in the first year of its life and assist in identifying areas for remedial attention, thus creating the conditions for the program to respond and attend to relationship opportunities and ruptures. While these techniques remain relatively underutilised by social work researchers, it is our view that SNA offers social workers not only a means of understanding connections between services but also the potential for wider application to social work inquiry. What follows is a summary of SNA and how its key elements relate to the construct of service integration.

\section{Social Network Analysis}

For over eighty years, SNA has provided a means of describing a broad range of relational phenomena (Kirke, 2009). However, its use has expanded exponentially in the last decade, spurred on by technological advances that have enabled the creation of graphic network images using computer programs such as Pajek (Batagelj \& Mrvar, 2011; De Nooy, Mrvar, \& Batageli, 2011), UCINET (Borgatti, Everett, \& Freeman, 2002; Borgatti, Everett, \& Freeman, 2006) and Gephi (Bastian, Heymann, \& Jacomy, 2009). SNA holds relevance for many academic disciplines in the social and health sciences (Borgatti, Mehra, Brass, \& Labianca, 
2009; Scott, 2013; Wasserman \& Faust, 1994). A plethora of diverse examples exist with researchers seeking to understand, for example, personal and support networks (Hill, 2002); sexual networks and the spread of HIV (Morris, Goodreau, \& Moody, 2007); networks protecting criminal behaviour (Browning, 2009); leadership networks (Hoppe \& Reinelt, 2010); the regional spread of infectious diseases, such as SARS (Meyers, Pourbohloul, Newman, Skowronski, \& Brunham, 2005) and the nature of terrorist networks (Sageman, 2004).

Wasserman and Faust's (1994) text on the methods and application of SNA identified the fundamental concepts of network analysis to be key structural characteristics and network processes. Kirke (2009) made clear that SNA is distinctive in that its fundamental unit of analysis is the relationship or the "dyadic tie" (p. 135) between two actors or nodes. Kirke further explained how SNA allows for the coding of actors and the nature of their relationships to reflect information such as gender or strength of relationship between actors. Recent research also recommended mixed-methods approaches in SNA research, arguing that both quantitative and qualitative data are needed when examining networks (Rice et al., 2014, p. 253).

Ennis and West (2010) outlined the elements of interest in a network to be "size, the connectedness of the actors, the concentration or dispersion of the actors, the accessibility of the network, the degree of clustering in the network", and the "heterogeneity" of the actors (p. 408). The level of connectedness in a simple network relates to the number of ties (oneway or reciprocal) between actors. This may range from zero (no actor having any connection to another) to a maximum number of connections when all actors are linked to each other in both directions. Of interest to us was the size of the bounded (closed) MHS consortium, a comparison of the views of managers and service providers, whether a hub (cluster) of service providers existed, and if service providers recommended other partners join the network of service providers to enhance the success of the program. Network processes include "(what is being exchanged or communicated in the network), contact frequency and degree of intimacy, the durability and intensity" of the relationships; and "the direction of the ties" (pp. 408-409), which may be uni- or bi-directional. In terms of network processes within the MHS consortium, the nature of relationships between service providers; the frequency of contact between service providers (weekly, fortnightly, monthly, ad hoc, or never); the direction of contact, and whether they shared information about formal or informal referrals were examined. 


\section{Social Networks, Social Network Analysis and Social Work}

As social workers contemplating the application of SNA to service integration, the relationship between social networks, analyses, and social work practice and research was important. Intuitively, these three elements are related and social work researcher Trevillion (2000) laid out these linkages by considering two propositions: that social work practice is complex and that social work research seeks to understand these complexities. He claimed that when a network approach that acknowledges social networks and associated knowledges is used, a strong foundation for social work practice and research is created. He suggested such a framework enables the production of "networked knowledge" and distinctive social work knowledges that allow for "multiple perspectives", "dialogue", "ownership" of knowledges by all involved, reflexivity, and the incorporation of key social work concerns such as "social justice”, meeting needs, "vulnerability" and "support” (pp. 514-516).

Almost thirty years ago, McIntyre argued the centrality of social networks to social work practice. McIntyre (1986) explained how the language of SNA rapidly "entered the practice lexicon" (p. 421) and became a tool for social work to describe network characteristics and explain complex interactions. Kirke (2009) argued that social workers have shown interest in SNA since the mid-70s and cited an early application by Garrison and Werfel (1977) who used social networks to assist clients to understand and strengthen their personal networks. This predated interest in social support networks generated by Scottish social work researcher, Seed (1990), who recommended network analysis to the profession by outlining its applications in the assessment of personal and support networks of clients in both community and residential settings when transitioning from hospital to community. Seed saw the potential for SNA to be used in the management, planning, and monitoring of services but conceded it was limited because it was used infrequently by social workers.

While social workers have a strong affinity with the concept of networks and have utilised relationship-mapping tools such as genograms (Dale, Smith, Norlin, \& Chess, 2009) and ecomaps (Bronfenbrenner, 1979) for decades, Kirke (2009) suggested the use of SNA in social work research is less common. Perhaps social work's lack of affinity with SNA's origins in sociometric analysis and graph theory may, in part, explain this. Heath, Fuller and Johnston (2009) made note of its rather different "toolkit and methodology" (p. 646) which may also explain some reluctance. 
Even so, a small number of social work researchers have used SNA. Webb (2008) employed SNA to examine participation in social care in the United Kingdom: this work is of major interest to our consideration of service integration. Webb not only demonstrated how the language of network analysis resonates for social work with terms such as "bridges or ties" (p. 277), "existence of a relationship", "frequency of interaction", and "value of the relationship" (p. 280) but he also referred to its use in measuring partnerships across time. Ennis' (2011) thesis and her work with West (Ennis \& West, 2010; Ennis \& West, 2012; Ennis \& West, 2013) utilised SNA to demonstrate change in the partnerships formed between organisations in the suburb of Ludmilla in Darwin in the Northern Territory, over a 19-month period. This work embedded SNA in community development activities and proved to be a useful modality for enhancing practice and measuring the efficacy of community development projects. Related to service integration, Blakeslee (2012) used SNA to measure the interconnectedness of relationships and the availability and transfer of resources in service provider and support networks of vulnerable young people transitioning out of state care. Bunger (2010) also provided a social work perspective on administrative service coordination, and proposed examining the fragmented nature of mental health service delivery using a variety of methods including SNA and Pajek software (Bunger, 2009). SNA has also been employed by teams of researchers located in North American schools of social work. Their recent studies have used SNA to explore the ways in which young people experiencing homelessness engage with employment services (Barman-Adihikari \& Rice, 2014), and the ways in which networks of influence impact on strategic activity and intent within large programs (Palinkas et al., 2013).

Although the number of social workers conducting SNA research is relatively small, there is no shortage of SNA conducted by researchers in other disciplines that inform social work practice and research across a broad range of areas. Examples include applying SNA to evaluate complex policy frameworks (Drew, Aggleton, Chalmers, \& Wood, 2011), to assess the impact of a youth coalition to prevent violence (Bess, Speer, \& Perkins, 2012), and to identify networks of people who are difficult to reach (Smith, 2013).

\section{Applying Social Network Analysis to Service Integration}

The integration of services is a significant policy direction in Australia (Flatau et al., 2014) and is frequently operationalised as a key performance indicator in health and human service programs. While varying terms such as joined up service delivery, seamless service delivery, continuum of care, and care coordination are used to describe these ways of working, we use 
the term service integration. Ye, Browne, Grdisa, Beyene, and Thabane (2012) deemed that service integration "involves the coordination of services provided by autonomous agencies and improves the organization and delivery of multiple services..." (p. 1).

Importantly, service integration is a socially constructed term, imbued with expectations such as improved outcomes for consumers, the avoidance of duplicated programs, no wrong door responses to complex needs, greater impact for the individual and community, and more efficient use of limited resources (Bell, Kinder, \& Huby, 2008; Browne Kingston, Grdisa, \& Markle-Reid, 2007; Ye et al., 2012). Coordinated multi-agency responses acknowledge consumers' multi-layered experiences and aim to provide contextdriven responses, rather than those that reinforce siloed or partitioned service delivery activities (Ling, 2002). A critical stance towards service integration recognises that limited evidence exists to support the apparently common sense benefits emerging from this approach (Jarrett, Stevenson, Huby, \& Stewart, 2009). Further, mapping and measuring changes in service integration within a group of organisations is complex (Ye et al., 2012, p. 2) and multiple research modalities and methods are required to capture impacts and changes.

While there is much interest in measuring service integration and its effectiveness, it remains a contested and "understudied" concept (Provan, Fish, \& Sydow, 2007, p. 479). The early work of Konrad (1996) deployed a continuum of integration and inspired the work of Browne et al. (2004) and Browne, Kingston, Grdisa, \& Markle-Reid (2007) who developed tools to measure service integration. Others have written extensively on the integration of services, with some focussing on measurement and some emphasising process evaluations (Ahgren \& Axelsson, 2005; Glasby, 2005; Kodner \& Spreeuwenberg, 2002; Ramsay, Fulop, \& Edwards, 2009). Various partnership assessment tools have also been developed, for example, the Partnership Tool developed by Weiss, Miller Anderson and Lasker (2002). In Australia, Flatau et al.'s (2013) work on service integration combined the work of Browne, Kingston, Grdisa and Markle-Reid (2007) and Weiss, Miller Anderson and Lasker (2002) to develop an integration survey.

Provan and colleagues investigated the effectiveness of inter-organisational networks (Provan, Fish, \& Sydow, 2007; Provan \& Milward, 2001). Their review of the empirical literature, which examined inter-organisational networks at the level of network analysis, identified only 26 studies in the 20 years from 1985 to 2005 (Provan, Fish, \& Sydow, 2007). Our own review of more recent literature shows that the use of SNA in the evaluation of 
inter-organisational relationships remains unusual although we were drawn to two recent projects. Fuller et al. (2007) found that SNA, in both diagrammatic and tabular presentations, provided a useful means to describe service and referral links in mental health services for farmers in rural New South Wales. A second study undertaken in Washington in the US by Davis, Koroloff, and Johnsen (2012) examined the impact of investing in improving the integration of mental health services for children transitioning from child and adolescent mental health services to adult mental health services. Using SNA, the study found that over time, the two separate mental health systems became better integrated.

As a cautionary note, there is a range of external barriers to achieving high levels of service integration. Policy rhetoric about service integration does not always acknowledge the context in which networks of service providers strive to better coordinate their services. In terms of the institutional backdrop, inherent challenges to strengthening informal relationships within service networks exist and include differences around organisations' protocols, procedures and resource management (Gilchrist, 2009; Kadushin, Lindholm, Ryan, Brodksy, \& Saxe, 2005). Gilchrist (2009) argued that the key characteristics of networks (strong interpersonal relationships; "boundary-spanning”, sharing resources, trust, "cooperation" and shared vision, p. 55) can be at odds with the key characteristics of individual services such as "formal procedures," control of resources, "accountability, bureaucratic arrangements, rules and relations, contracts and directives” (p. 54). She also made the point that resources are required to harness harmonious, collegial ways of relating especially in a network of service providers situated in organisations with little interest or capacity for such investment, a point often overlooked in the compelling rhetoric of service integration. Here, we suggest that SNA can provide evidence of the need for greater investment in strengthening partnerships at a network level.

\section{Method}

The research team met with the MHS consortium and the research reference group (a subgroup of MHS consortium members) to shape the research plan. The key objective was to understand how well MHS consortium partners engaged with each other to meet the health and wellbeing needs of consumers. A mixed methods design was employed.

\section{Participants}

A list of 22 prospective participants (a service provider and manager from each of the 11 MHS consortium partners in the bounded network) was drawn up by the MHS manager. The 
manager emailed consortium partners to apprise them of the research and to indicate that a researcher would invite prospective participants to participate. In addition and because of their key roles, the independent chair of the consortium and two community engagement workers were also invited to participate. Table 1 summarises participants and organisations. Ethics approval was obtained from the University Human Rights Ethics Committee in February 2014.

[Insert Table 1. Participants and their Organisations/Functions]

\section{Data Collection Tools and Procedures}

Data collection first involved a review of secondary documentation about the MHS' strategic approach; its community engagement activities; its guidelines on delivery of care and local service directories. This enabled the researchers to describe the MHS program in more detail and also informed the development of the semi-structured interview. A 12-question interview schedule was developed. Three questions in a tabular format collected quantitative network data about information exchange (type, frequency, and direction to and from) and referral pathways (to and from), and nine questions asked for qualitative data about enablers and barriers to service integration, quality of working relationships, and other service partners external to the consortium who were deemed important to improving service integration. Following each interview, all participants reviewed the data to confirm its accuracy. The Youth NGO was the only consortium member unable to participate. Data about this organisation were provided by others and the researchers made a decision that it was reliable enough to include. Therefore it is acknowledged as proxy data.

\section{Data Analysis}

Data analysis first involved the preparation of datasets suitable for the UCINET software program. Notepad text files containing data about the direction and frequency of information sharing as well as information about referral origins were prepared and converted to UCINET input files. These were loaded into UCINET and its Netdraw facility utilised to build pictorial representations of the network. Second, UCINET's capacity to calculate sociometric measures of centrality through its menu options (indegree-number of ties coming into an organisation; outdegree - number of ties going out; betweenness - the paths that pass through an organisation and connect it to other pairs of organisations in the network thus 
making it a hub or not), cohesion (the level of network connectedness) and density (the number of ties in the network as a proportion of maximum number of ties) enabled the extraction of numerical data about the network to describe the degrees of connection between organisations. Finally, qualitative data were analysed using thematic analysis drawing on concepts from the literature about service integration. The researchers worked, first independently and then in pairs, to analyse key themes in the qualitative data question by question.

\section{Results}

Nineteen people were interviewed including nine service providers, seven managers, two community engagement workers from organisations and the independent chair. Six people were interviewed by phone and the remainder face-to-face. Although graphical representations of both information exchange and referral pathways for managers and service providers were produced, only graphs about information exchange are shown here.

\section{Information Exchange}

Figures 1 and 2 show the direction and frequency of information exchange (formal and informal referrals and clinical and other service information) between the MHS consortium managers (Figure 1) and service providers (Figure 2). The size of arrows and width of lines reflect the direction and frequency of communications between organisations. The thickest lines and arrows refer to weekly communication (4.0), and then thinning and reducing for fortnightly (3.0), monthly (2.0) and ad hoc communication (1.0). The absence of a line between organisations reflects the stated view that no information was being shared between these organisations.

As can be seen from Figures 1 and 2, the NGO Community Support, the MHS host organisation, the lead agency and two of the government mental health agencies had the most frequent communication and information exchange with each other, and with more organisations. In particular, the greater number of ties in Figure 2 compared to Figure 1 suggests service providers reported more widespread information exchange than managers.

[Insert Figure 1 Direction and Frequency of Information Exchange between Managers]

[Insert Figure 2 Direction and Frequency of Information Exchange between Service Providers] 


\section{Centrality, Cohesion and Density}

Using UCINET's sociometric measures of centrality, cohesion and density, calculations were made for both managers and service providers (see Tables 2 and 3). Unlike the graphical representations, these links were analysed on a dichotomous scale (absent or present) and hence did not take account of frequency of communication. Therefore, for example, in Table 2, the Job Service organisation exhibits a high outdegree although all but one of its communications with consortium members was ad hoc.

[Insert Table 2 Measure of Centrality from Perspectives of Managers and Service Providers]

[Insert Table 3 Measures of Cohesion and Density from Perspectives of Managers and Service Providers]

As expected, service providers and managers viewed MHS as having a high degree of influence in the network although there were differences between managers and service providers. Table 2 indicates the betweenness measure for managers was highest for the NGO Community Support followed by the lead agency and then the MHS host agency. However, reflective of the emphasis on service provision, Table 2 also indicates that service providers saw the MHS host agency as having the highest betweenness measure followed by two of the government mental health services (GOV MH 1 and GOV MH 3), and then the NGO Community Support was deemed to be relatively influential. Further, the measures of network cohesion and density revealed some differences between manager and service provider perspectives (see Table 3). In general, the network data demonstrates that managers had a more optimistic view of the consortium's cohesion than service providers.

\section{Nature of Relationships}

The analysis of the qualitative data revealed that both service providers and managers were satisfied with the level of service integration for MHS with the vast majority of service providers, managers, and community development workers speaking of the MHS host agency as a "really proactive" hub of "very friendly and collaborative" people, central to the development of positive informal and formal working relationships within the consortium.

The key theme to emerge from the qualitative data was the importance of strong oneto-one organisational relationships and the deep connection between service providers at the "grass-roots" network level. Strong and supportive working relationships between service 
providers were described as facilitating easy communication and informal exchange of information of all types although this success was seen to be partly due to a high level of motivation for ensuring the provision of quality networked services. These good working relationships were said to enable more effective management of crises and assisting in the smooth transition between services for consumers. Participants indicated that a number of informal and formal mechanisms facilitated the development of these relationships and the existence of formal training opportunities within the network was seen as building knowledge as well as enabling face-to-face relationship-building for service providers.

In addition, tensions between government and non-government organisations, as outlined by Gilchrist (2009), were also described by participants. Innate differences between procedures around information sharing, the role of the families of consumers, the management of risk, lines of accountability, types of control, and sharing of resources were seen as barriers to service integration and likely to persist. Participants spoke about minimising these barriers with good communication and by formalising one-to-one partnership agreements. When asked if there were new partners central to the success of the MHS program, more than 20 potential new partners/sectors were identified. These included: accommodation/housing groups; Indigenous organisations; family and carer organisations; and key government organisations like Centrelink.

\section{Discussion}

The analysis of both quantitative and qualitative data indicated a new and motivated consortium aspiring to maintain strong and supportive working relationships, grow its social capital and expand its network. The value in the use of SNA was its graphical and tabular representations of the MHS consortium relationships that provide data about the key roles of MHS as well as three to four other organisations in the exchange of information. Such information is not generally available in health service data sets. Also of interest were the different perspectives of managers and service providers highlighted by the network data. These differences were not so evident in the qualitative data which, in general, illustrated a slightly more favourable impression of the nature of information exchange for all.

Studies of service integration are highly topical. As we write this paper, the landscape for health, mental health, and homelessness services in Australia is volatile. The very uncertain budgetary environment sits alongside an increasing demand for integrated services, growing waiting lists, high staff turnover, and State and Commonwealth funding retractions 
in health and human services. As observers, we saw the positive impact of attempts to improve service integration. By repeating SNA in say 12 months' time, changes could be identified in network relationships, highlighting points for further investigation into the mechanisms needed to build integrated systems that work and are sustainable. Contrary to the noted limitation of SNA that it might "create undue emphasis on [its] good effects" (McIntyre, 1986, p. 423), we believe that the utilisation of SNA offers a great deal more and certainly does not need to privilege institutional discourse or official ways of knowing. Indeed, its ability to represent relational activities, without attributing interests, can provide much-needed evidence for advocacy to negotiate and collaborate with governments and other funders.

However, the snapshot data afforded by SNA are only of assistance when dialogue about such data occurs between actors in the network. While SNA illustrates the traced network between actors and a thematic analysis generates information about actors' views, neither focus on what is circulating or how the network produces shared meanings. We suggest that further analysis could use actor network theory (ANT), a network tracing activity that builds on ego centric networks to complement SNA. By listening to human actors, reading policy, procedures and referral texts, the researchers can include language, objects and symbols to explain where language comes from and what actors are actually doing. Actor network theory (Callon, 1986; Latour, 2005) also encourages reflexivity, examining the network's own language that develops as actors give accounts of how they behave in relation to the network. ANT records whether one account leads to other accounts or if it interrupts the growth of a network.

Finally, we make mention of the ethical challenges intrinsic to the conduct of social network research. Kadushin (2012) made the point that network analysis sometimes involves acquiring information indirectly about actors who can be individuals or organisations, as with the Youth NGO mentioned earlier. One might also utilise available documentation about attendance at consortium meetings over a given time period. Thus, when SNA is applied, levels of participation are shown without the people necessarily being aware that information about their attendance is being used in this way. Yet, this information is key when networks are newly emerging and developing the conditions for collaboration, particularly as this information can invite the network to ask "are the right partners at the table"? As Kadushin said, network analysis makes "visible what was not visible before and reveals connections [or lack thereof] between individuals and groups who may not have wanted that information to 
be made public" (p. 188). When faced with ethical dilemmas of this kind, he suggested focusing on the benefits and identifying who benefits from the information in the hope that these gains will overwhelm any harm that may ensue.

Service integration, social networks, and actors are all social constructs. As such they are contestable, and contain uncertainties (Latour, 2005) that interest us as researchers. As social work researcher Dean (2012) reminds us "we can never fully separate our interests and values from our observations...multiple understandings are possible" (p. 77). Hence, a combination of SNA and qualitative data complemented by ANT may provide a means of tracking the influence of actors' interests. Kadushin (2012) makes the point that networks are highly complex and that SNA alone cannot capture all elements.

\section{Conclusion}

In our view, SNA itself holds much more for social work practice and research than has been recognised to date. In this paper, we illustrate its value for social workers investigating the complex phenomenon of service integration. Employing SNA can provide answers to "what" and "who" questions. By combining these "what" and "who" questions with repeated data collections and ensuring open dialogue, we can examine "when." Combining SNA and qualitative data analysis means that lead agencies and consortium network members can review the structure, process, and functioning of their networks. Together, they can posit some possible answers to the "why" and "how" questions, and attend to problematic relationships by engaging in relationship repair during the life of a project. With many national and local policy programs incorporating ideas of participation, collaboration and partnership, mixed methods approaches can strengthen service integration. Service partners, consumers, community organisations and groups, who are effective in shaping program processes and outcomes, are more likely to remain involved and contribute to the program's sustainability. SNA also offers potential to be an advocacy tool, as Chambon and Irving (1999) said, to "go beneath the smooth surface of things" (p. 260). Combined with qualitative data, it provides not only a visual but also descriptive means to highlight the impact of the contexts in which social workers operate.

\section{Acknowledgements}


We recognise and thank the lead agency and all others in the consortium for being willing to work with us and to share information about their endeavours to strengthen partnerships and improve coordination of services. We would also like to thank Gretchen Ennis and Malcolm Alexander for their encouragement and for sharing their experiences of SNA and their use of Pajek and UCINET software. We also wish to thank Nicole Campbell, a social work student in our School, who so ably assisted with the research project as well as this paper.

\section{References}

Ahgren, B., \& Axelsson, R. (2005). Evaluating integrated health care: A model for measurement. International Journal of Integrated Care. Retrieved from: http://www.ijic.org

Barman-Adhikari, A., \& Rice, E. (2014). Social networks as the context for understanding employment services utilization among homeless youth. Evaluation and Program Planning, 45(0), 90-101. doi:http://dx.doi.org/10.1016/j.evalprogplan.2014.03.005

Bastian, M., Heymann S., \& Jacomy M. (2009). Gephi: An open source software for exploring and manipulating networks. Retrieved from: http://gephi.org/publications/gephi-bastian-feb09.pdf

Batagelj,V., \& Mrvar, A. (2011). PAJEK: Program for analysis and visualization of large networks (Version 2.02). Ljubljana. Retrieved from http://pajek.imfm.si/doku.php?id=download

Bell, K., Kinder, T., \& Huby, G. (2008). What comes around goes around: On the language and practice of "integration" in health and social care in Scotland. Journal of Integrated Care, 16(4), 40-48. doi:10.1108/14769018200800032

Bess, K. D., Speer, P. W., \& Perkins, D. D. (2012). Ecological contexts in the development of coalitions for youth violence prevention: An organizational network analysis. Health Education \& Behavior, 39(5), 526-537. http://dx.doi.org/:10.1177/1090198111419656 
Blakeslee, J. (2012). Expanding the scope of research with transition-age foster youth: Applications of the social network perspective. Child \& Family Social Work, 17, 326336. doi:10.1111/j.1365-2206.2011.00787.x

Borgatti, S. P., Everett, M. G., \& Freeman, L. C. (2002). Ucinet for Windows: Software for Social Network Analysis. Harvard, MA: Analytic Technologies. Retrieved from: www.analytictech.com

Borgatti, S. P., Everett, M. G., \& Freeman, L. C. (2006). UNICET 6 Social network analysis software [Computer software] East Huntington: INSNA.

Borgatti, S. P., Mehra, D. J., \& Labianca, G. (2009). Network analysis in the social sciences. [Review]. Science, 323(5916), 892-895. doi:10.1126/science.1165821.

Bronfenbrenner, U. (1979). The ecology of human development: Experiments by nature and design. Cambridge: Harvard University Press.

Browne, G., Kingston, D., Grdisa, V., \& Markle-Reid, M. (2007). Conceptualization and measurement of integrated human service networks for evaluation. International Journal of Integrated Care, 7, 1-6. Retrieved from: http://www.ijic.org/

Browne, G., Roberts, J., Gafni, A., Byrne, C., Kertyzia, J., \& Loney, P. (2004). Conceptualizing and validating the human services integration measure. International Journal of Integrated Care, 4(2), 1-7. Retrieved from: http://www.ncbi.nlm.nih.gov/pmc/articles/PMC1393260/?report=classic

Browning, C. (2009). Illuminating the downside of social capital: Negotiated coexistence, property crime, and disorder in urban neighbourhoods. American Behavioral Scientist, 52, 1156-1578. doi:10.1177/0002764209331526

Bunger, A. C. (2009). Partnership development among mental health agencies. St. Louis: Washington University. Retrieved from http://student.systemdynamics.org/wp/wpcontent/ulf/2009-wiki-proceedings/Bunger.pdf

Bunger, A. C. (2010). Defining service co-ordination: A social work perspective. Journal of Social Service Research, 36(5), 385-401. doi:10.1080/01488376.2010.510931

Callon, M. (1986). Some elements of a sociology of translation: Domestication of the scallops and the fisherman of St Brieuc Bay. In J. Law (Ed.). Power, action and belief: A new sociology of knowledge? (pp. 196-223). London: Routledge \& Kegan Paul.

Chambon, A. S., \& Irving, A. (1999). Conclusion: Issues to look forward to. In A. S. Chambon, A. Irving \& L. Epstein (Eds.), Reading Foucault for social work (pp. 259267). New York: Columbia University Press. 
Dale, O., Smith, R., Norlin, J. M., \& Chess, W. A. (2009). Human behavior and the social environment: Social systems theory (6th ed.). Boston: Pearson Allyn \& Bacon.

Davis, M., Koroloff, N., \& Johnsen, M. (2012). Social network analysis of child and interorganizational connections. Psychiatric Rehabilitation Journal, 35(3), 262-272. doi: $10.2975 / 35.3 .2012 .265 .272$

Dean, R. (2012). Becoming a social constructivist: From Freudian beginnings to narrative ends. In Witkin, S. (Ed) Social construction and social work practice interpretations and innovations. New York: Columbia University Press.

De Nooy, W., Mrvar, A., \& Batageli, V. (2011). Exploratory social network analysis with PAJEK (2nd ed.). Cambridge: Cambridge University Press.

Drew, R., Aggleton, P., Chalmers, H., \& Wood, K. (2011). Using social network analysis to evaluate complex policy network. Evaluation, 17(4), 383-394. doi:10.1177/1356389011421699

Ennis, G. (2011). Neighbourhood networking: A critical social work approach to "creating community" in a culturally diverse setting. (Unpublished doctoral dissertation). Charles Darwin University, Darwin, NT

Ennis, G., \& West, D. (2010). Exploring the potential of social network analysis in assetbased community development practice and research. Australian Social Work, 63(4), 404-417. doi: 10.1080/0312407X.2010.508167

Ennis, G., \& West, D. (2012). Using social network analysis in community development practice and research: A case study. Community Development Journal, 48(1), 40-57. doi: $10.1093 / \mathrm{cdj} / \mathrm{bss} 013$

Ennis, G., \& West, D. (2013). Community development and umbrella bodies: Networking for neighbourhood change. British Journal of Social Work. doi:10.1093/bjsw/bct010

Flatau, P., Conroy E., Thielking, M., Clear, A., Hall, S., Bauskins, A., \& Farrugia, M. (2013). How integrated are homelessness, mental health and drug and alcohol services in Australia? Retrieved from www.ahuri.edu.au/publications

Fuller, J., Kelly, B., Sartore, G., Fragar, L., Tonna, A., Pollard, G., \& Hazell, T. (2007). Use of social network analysis to describe service links for farmers' mental health. The Australian Journal of Rural Health, 15(2), 99-106. doi:10.1111/j.14401584.2007.00861.x

Garrison, J., \& Werfel, S. (1977). A network approach to clinical social work. Clinical social work, 5, 108-117. Retrieved from http://link.springer.com.dbgw.lis.curtin.edu.au/article/10.1007/BF02144236 
Gilchrist, A. (2009). The well-connected community: A networking approach to community development (2nd ed.). Bristol: The Policy Press.

Glasby, J. (2005). The integration dilemma: How deep and broad to go? Journal of Integrated Care, 13(5), 27-30.

Heath, S., Fuller, A., \& Johnston, B. (2009). Chasing shadows: Defining network boundaries in qualitative social network analysis. Qualitative Research, 9(5), 645-661. doi: $10.1177 / 1468794109343631$

Hill, M. (2002). Network assessments and diagrams. Journal of Social Work, 2(2), 233-254. doi: $10.1177 / 146801730200200207$

Hoppe, B., \& Reinelt, C. (2010). Social network analysis and the evaluation of leadership networks. The Leadership Quarterly, 21, 600-619. doi: 10.1016/j.leaqua.2010.06.004

Jarrett, D., Stevenson, T., Huby, G., \& Stewart, A. (2009). Developing and implementing research as a lever for integration: The impact of service context. Journal of Integrated Care, 17(5), 38-48. doi: 10.1108/14769018200900038

Kadushin, C. (2012). Understanding social networks: Theories, concepts, and findings. New York: Oxford University Press.

Kadushin, C., Lindholm, M., Ryan, D., Brodsky, A., \& Saxe, L. (2005). Why it is so difficult to form effective community coalitions? City \& Community, 4(3), 255-275. doi: 10.1111/j.1540-6040.2005.00116.x

Kirke, D. M. (2009). Social network analysis. In S. A. Webb \& M. Gray (Eds.), Social work: Theories and methods (pp. 131-141). London: Sage Publications.

Kodner, D., \& Spreeuwenberg, C. (2002). Integrated care: Meaning, logic, applications, and implications-A discussion paper. International Journal of Integrated Care. Retrieved from http://www.ijic.org/>p. 2

Konrad, E. (1996) A multidimensional framework for conceptualizing human services integration initiatives. New Directions for Evaluation, 69, 5-19

Latour, B. (2005). Reassembling the social: An introduction to actor-network-theory. New York: Oxford University Press.

Ling, T. (2002). Delivering joined up government in the UK: Dimensions, issues and problems. Public Administration, 80(4), 615-642.

McIntyre, E. (1986). Social work networks: Potential for practice. Social Work, 31(6), 421426. doi:10.1093/sw/31.6.421 
Meyers, L. A., Pourbohloul, B., Newman, M. E. J, Skowronski, D. M., \& Brunham, R. C. (2005). Network theory and SARS: Predicting outbreak diversity. Journal of Theoretical Biology, 232, 71-81. doi: 10.1016/j.jtbi.2004.07.026

Morris, M., Goodreau, S., \& Moody, J. (2007). Sexual networks, concurrency and STD/HIV. In K. K. Holmes, P. A. Mardh, P. F Sparling, S. M. Lemon, W. E. Stamm, P. Piot \& J. Wasserheit (Eds.). Sexually transmitted diseases (4th ed., pp. 109-125). New York: McGraw-Hill

Palinkas, L., Holloway, I., Rice, E., Brown, C., Valente, T., \& Chamberlain, P. (2013). Influence network linkages across implementation strategy conditions in a randomized controlled trial of two strategies for scaling up evidence-based practices in public youth-serving systems. Implementation Science, 8(1), 133.

Provan, K. G., Fish, A., \& Sydow, J. (2007). Interorganizational networks at the network level: A review of the empirical literature on whole networks. Journal of Management, 33(3): 479-516.

Provan, K. G., \& Milward, H. B. (2001). Do networks really work? A framework for evaluating public-sector organizational networks. Public Administration Review 61(4): 414-423.

Ramsay, A., Fulop, N., \& Edwards, N. (2009). The evidence base for vertical integration in health care. Journal of Integrated Care, 17(2), 141-146.

Rice, E., Holloway, I., Barman-Adhikari, A., Fuentes, D., Hendricks Brown, C., \& Palinkas, L. (2014). A mixed methods approach to network data collection. Field Methods, 26(3), 252-268.

Rose, N. (1999). Powers of freedom. Cambridge: Cambridge University Press.

Sageman, M. (2004). Understanding terror networks. Philadelphia: University of Pennsylvania Press.

Scott, J. (2013). Social network analysis (3rd ed.). London: Sage Publications.

Seed, P. (1990). Introducing network analysis in social work. London: Jessica Kingsley Publishers.

Smith, S. (2013). Social network boundaries and tricky to access populations: A qualitative approach. International Journal of Social Research Methodology, 1-11. doi: $10.1080 / 13645579.2013 .820076$

Trevillion, S. (2000). Social work, social networks and network knowledge. British Journal of Social Work, 30(4), 505-517. doi: 10.1093/bjsw/30.4.505 
Wasserman, S., \& Faust, K. (1994). Social network analysis: Methods and applications. Cambridge: Cambridge University Press.

Webb, S. A. (2008). Modelling service user participation in social care. Journal of Social Work, 8(3), 269-290. doi: 10.1177/1468017808091040

Weiss, E., Miller Anderson, R., \& Lasker, R. D. (2002). Making the most of collaboration: Exploring the relationship between partnership synergy and partnership functioning. Health Education \& Behavior, 29(6), 683-698. doi: 10.1177/109019802237938

Witkin, S. (Ed.). (2012). Social construction and social work practice: Interpretations and innovations. New York: Columbia University Press.

Ye, C., Browne, G., Grdisa, V. S., Beyene, J., \& Thabane, L. (2012). Measuring the degree of integration for an integrated service network. International Journal of Integrated Care, 12, 1-9. Retrieved from http://www.ncbi.nlm.nih.gov/pmc/articles/PMC3601536/ 
Table 1 Participants and their Organisations/Functions

\begin{tabular}{llcccc}
\hline Organisations $^{\text {a }}$ & Organisation Function & $\begin{array}{c}\text { Service } \\
\text { Providers }\end{array}$ & Managers & $\begin{array}{c}\text { Community } \\
\text { Engagement } \\
\text { Workers }\end{array}$ & Other \\
\hline MHS & Host agency/hub & $\mathrm{X}$ & $\mathrm{X}$ & $\mathrm{X}$ & - \\
Lead Agency & Counselling service & $\mathrm{X}$ & $\mathrm{X}$ & - & - \\
AOD & Alcohol and other drug org & $\mathrm{X}$ & $\mathrm{X}$ & - & - \\
NGO Comm Supp & Community services network & $\mathrm{X}(\mathrm{n}=2)$ & $\mathrm{X}$ & - & - \\
Local Council & Community support services & $\mathrm{X}$ & $\mathrm{X}$ & - & - \\
Job Service & Access to employment & $\mathrm{X}$ & - & - & - \\
GOV MH3 & Adult mental health service & - & - & $\mathrm{X}$ & - \\
PHS & Primary health care service & - & $\mathrm{X}$ & - & - \\
GOV MH1 & Child mental health service & $\mathrm{X}$ & $\mathrm{X}$ & - & - \\
GOV MH2 & Youth mental health service & $\mathrm{X}$ & - & - & - \\
NGO Youth & Community support service & - & - & - & - \\
Independent Chair & Consortium chair & - & - & - & $X$ \\
\hline
\end{tabular}

Note. ${ }^{\text {a }}$ Organisations are represented by codes in order to maintain their anonymity 
Table 2 Measures of Centrality from Perspectives of Managers and Service Providers

\begin{tabular}{lcc|cc|cc}
\hline Organisations & \multicolumn{2}{c|}{ Indegree ties } & \multicolumn{2}{c|}{ Outdegree ties } & \multicolumn{2}{c}{ Betweenness } \\
& Managers & $\begin{array}{c}\text { Service } \\
\text { providers }\end{array}$ & Managers & $\begin{array}{c}\text { Service } \\
\text { providers }\end{array}$ & Managers & $\begin{array}{c}\text { Service } \\
\text { providers }\end{array}$ \\
\hline MHS & 6.00 & 8.00 & 9.00 & 9.00 & 3.20 & 9.36 \\
Lead Agency & 6.00 & 5.00 & 9.00 & 7.00 & 4.03 & 2.95 \\
AOD & 5.00 & 5.00 & 6.00 & 5.00 & 0.20 & 1.74 \\
NGO Comm & 6.00 & 6.00 & 10.00 & 7.00 & 5.20 & 3.24 \\
Supp & 2.00 & 3.00 & 6.00 & 6.00 & 0.00 & 1.42 \\
Local Council & 5.00 & 3.00 & 0.00 & 10.00 & 0.00 & 2.53 \\
Job Service & 6.00 & 7.00 & 0.00 & 7.00 & 0.00 & 3.33 \\
GOV MH3 & 3.00 & 8.00 & 9.00 & 0.00 & 0.45 & 0.00 \\
PHS & 5.00 & 8.00 & 7.00 & 7.00 & 0.92 & 4.07 \\
GOV MH1 & 6.00 & 6.00 & 0.00 & 4.00 & 0.00 & 0.37 \\
GOV MH2 & 6.00 & 4.00 & 0.00 & 0.00 & 0.00 & 0.00 \\
NGO Youth &
\end{tabular}

Note. The betweenness score counts the number of shortest paths between two other actors that pass through the focal actor. It is an indicator of how important that focal actor is to the cohesion and connectivity of the network. 
Table 3 Measures of Cohesion and Density from Perspectives of Managers and Service Providers Level Cohesion

\begin{tabular}{lccc} 
& Average Degree & Density & Average Distance \\
\hline Managers & 5.09 & 0.51 & 1.20 \\
Service Providers & 4.75 & 0.68 & 1.34
\end{tabular}

Note. The average degree calculates the number of ties per organisation; the density calculates the number of ties between organisations as a proportion of the total number of possible ties; the average distance is the average path length and takes the distance (number of steps) of all the shortest possible paths in the network and averages it by the number of paths. A shorter average distance indicates a more cohesive network.

Average degree and average distance are most useful when comparing networks of different sizes. 
Figure 1 Direction and Frequency of Information Exchange between Managers

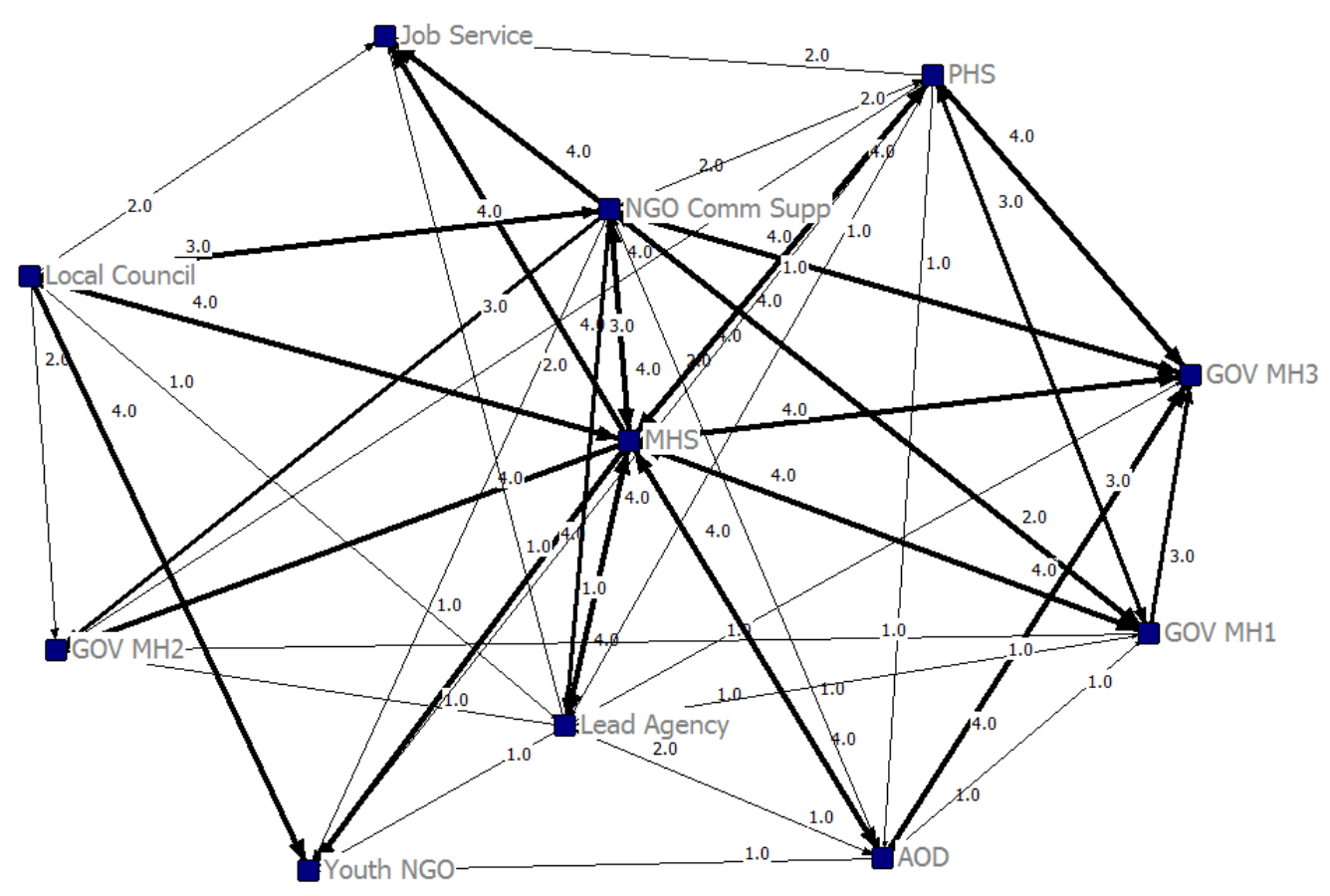


Figure 2 Direction and Frequency of Information Exchange between Service Providers

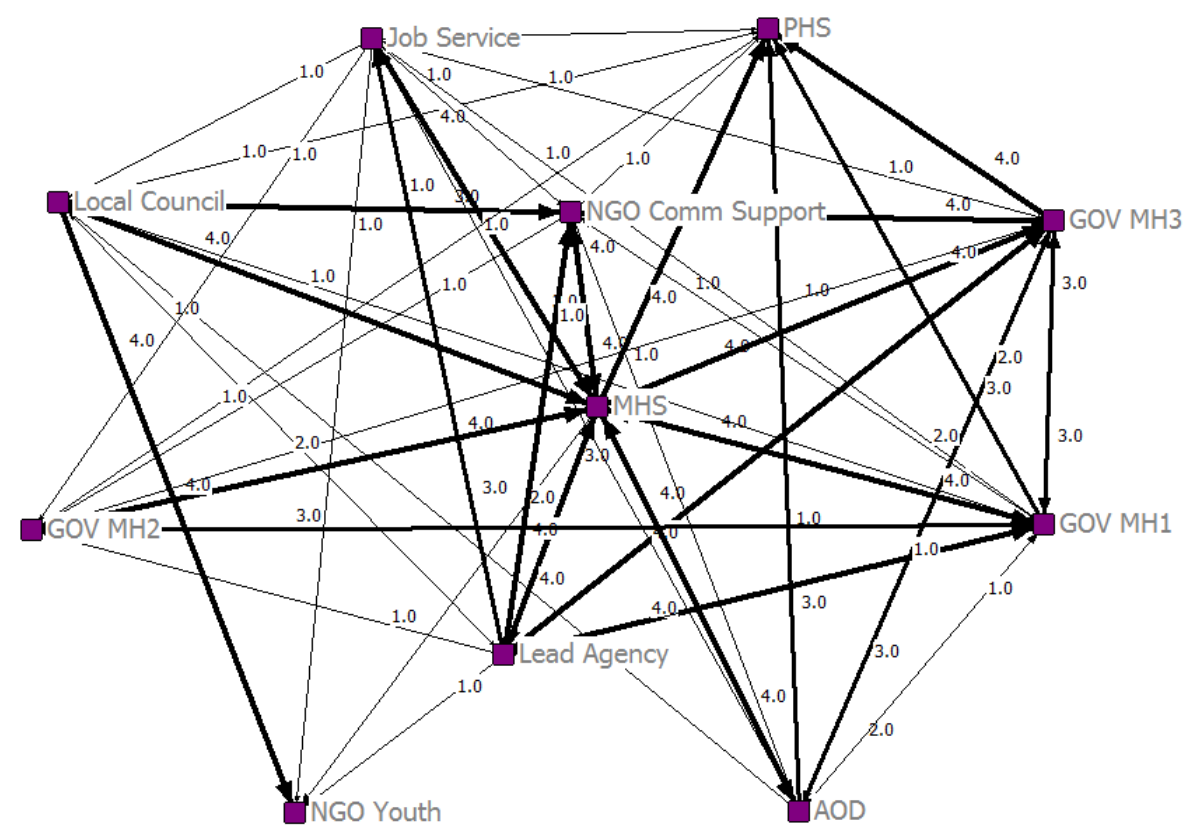

